\title{
Numerical Simulation of Humidity Distribution in Levee Road Subgrade
}

\author{
Wei Hao ${ }^{1, a^{*} \text {, Zhengqi Zhang }}{ }^{2, b}$, Dongsheng Chen ${ }^{3, c}$ and Jianping Zhu ${ }^{4, d}$ \\ ${ }^{1}$ Chang'an University, Middle section of er huan street, Xi'an, China \\ ${ }^{2}$ Chang'an University, Middle section of er huan street, Xi'an, China \\ ${ }^{3}$ The Third Railway Survey and Design Institute Group Corporation, \\ Minjiang Street 10, Tianjing, China \\ ${ }^{4}$ China Merchants Chongqing Communications Research \& Design Institute CO.,LTD \\ China Merchants Building, No.33 Xuefu Avenue, Nan'an Distract, Chongqing \\ a xianhw@163.com, b z_zhengqi@126.com, ${ }^{\mathrm{c}} 23106734 @ q q . c o m,{ }^{d}$ zhujianping@cmhk.com
}

Keywords: levee road, FEM, Humidity Distribution, seepage

Abstract. A levee road is a component of a levee project. The subgrade of a levee road is the levee itself and usually it is submerged in the water. A special attention has been paid for slop stability and seepage of levee road under submerged condition during design and construction phases. This study investigated the effect of precipitation on humidity distribution in a levee road subgrade using the commercial finite element (FEM) package, GEO-Studio. The saturated-unsaturated seepage model has been adopted in the SEEP/W module to conduct numerical simulation on the humidity distribution of levee subgrade. Different ground water level on the river side was used. The effect of precipitation was also included. The humidity distribution in the simulated levee subgrade was presented through counter maps.

\section{Introduction}

A levee road is a component of a levee project. It is constructed by paving a pavement on the top of a levee [1]. The subgrade of a levee road is the levee itself and usually it is submerged in the water, which is the primary difference between levee roads and normal roadways. Therefore, a special attention has been paid for slop stability and seepage of levee road under submerged condition during design and construction phases. Usually, a levee is constructed with low permeability materials, such as clay, to prevent seepage. The slope of a levee is determined through calculation according to the design level, construction materials, foundation, river waves, structure of levee body, slope protection, crest elevation, construction techniques and etc. Compare to normal roads, the slop of a levee road is slow. The height of a levee road is higher than a normal road.

According to the highway design standards, the humidity condition of a subgrade can be divided into three levels, dry, moist and wet [2]. The mechanical property of subgrade varies significantly at different humidity conditions. To ensure the subgrade stability, in most cases it is required that a subgrade remains at dry or moist conditions [3-4]. A levee is subjected to scour and erosion on the river sides. The pore water pressure and the seepage pressure within the levee subgrade change according to the water surface level. The subgrade humidity affects pore water pressure and the seepage pressure. These parameters closely correlate to the strength and the stability of the subgrade and therefore influence the overall performance of a levee roadway [5]. Analysis of subgrade humidity is of great importance to ensure the stability of levee road subgrade.

The finite element method (FEM) has become a powerful tool for subgrade humidity analysis, due to its ability to solve a complex problem domain and include almost all governing equations and material constitutive models. The SEEP/W module in the GEO-Studio FEM software package is a common tool in the geotechnical engineering to simulate the water movement in the ground. It has been used in a previous study to analyze the subgrade humidity field evolution with different 
compaction models for normal road [6]. The effects of precipitation duration and density on subgrade humidity were also analyzed through SEEP/W [7]. A similar study was also performed for a subgrade using unsaturated soil model [8]. However, in these previous studies, the FEM method was used for normal highway subgrade. The levee subgrade with its unique cross section profile and adjacent ground water condition was not considered.

In this study, a saturated-unsaturated seepage model has been adopted in the SEEP/W module to conduct numerical simulation on the humidity distribution of levee subgrade. Different ground water level on the river side was used. The effect of precipitation was also included. The humidity distribution in the simulated levee subgrade was presented through counter maps.

\section{FEM model configuration}

In this study, the FEM model was configured according to the levee road on the side of Wei River near Xingping in Shaanxi province, China. The levee was design to resist 30-year flood in rural areas and 100-year in the city area. The height of levee was 4-6 $\mathrm{m}$ with the slope ratio of 1:3 (height to width). The geometry model of the levee load is shown in Figure 1. The width on the top of the levee subgrade is $20 \mathrm{~m}$. The height of the levee is $5 \mathrm{~m}$. The levee road is paved with asphalt layer and the width of shoulder is $1 \mathrm{~m}$. The depth of the foundation is $5 \mathrm{~m}$.

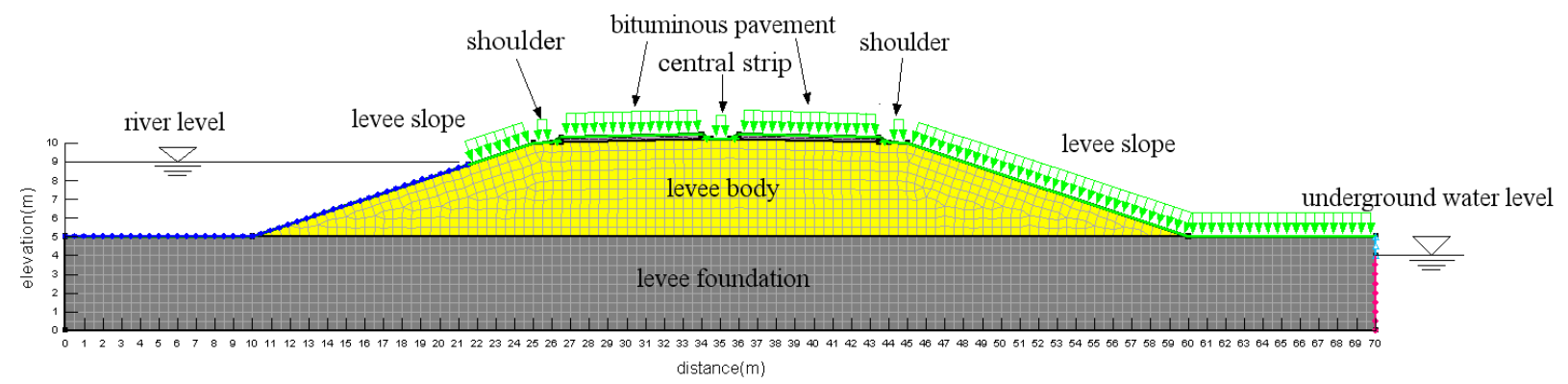

Figure 1 Numerical model of levee road subgrade humidity field

As shown in Table 1, three water levels were considered on the river side, flood level, median water level and low water level. The water level on the dry side was assumed to be fixed at $-1 \mathrm{~m}$.

Table1 River water level setting

\begin{tabular}{ccc}
\hline & Water level on the river side $(\mathrm{m})$ & Water level on the dry side $(\mathrm{m})$ \\
\hline Flood level & 4 & -1 \\
Median water level & 2 & -1 \\
Low water level & 0 & -1 \\
\hline
\end{tabular}

Laboratory tests were conducted to measure the properties of soil sampled from the Wei River levee subgrade. The sieving analysis was performed to measure the grain distribution and the result is shown in Table 2. Tests were also performed to determine the Atterberg limits, plastic limit $13.5 \%$ and liquidity limit $20.3 \%$. The moisture content was $7.6 \%$ and the consistency was $7.6 \%$. Types of soil, volumetric properties and permeability coefficient are listed in Table 3. The Fredlund-Xing model was adopted to simulate the behavior of soil and parameters used for each types of soil are also listed in Table 3. 
Table 2 Soil sieving analysis

\begin{tabular}{|c|c|c|c|c|c|c|c|c|c|}
\hline \multicolumn{3}{|c|}{ grain size $(\mathrm{mm})$} & 10 & 5 & 2 & 1 & 0.5 & 0.25 & 0.075 \\
\hline \multicolumn{3}{|c|}{ Percent Passing $(\%)$} & 100 & 100 & 99.8 & 99.5 & 85.8 & 78.2 & 36.7 \\
\hline \multicolumn{10}{|c|}{ Table3 Seepage calculation parameters of levee materials } \\
\hline \multirow{2}{*}{\multicolumn{2}{|c|}{ Type of soil }} & \multirow{2}{*}{$\begin{array}{c}\text { specific } \\
\text { gravity } \\
\left(G_{S}\right)\end{array}$} & \multirow{2}{*}{$\begin{array}{l}\text { void } \\
\text { ration } \\
\text { (e) }\end{array}$} & \multirow{2}{*}{\multicolumn{2}{|c|}{$\begin{array}{c}\text { water } \\
\text { content of } \\
\text { saturated } \\
\text { soil }(\%)\end{array}$}} & \multirow{2}{*}{$\begin{array}{c}\text { permeability } \\
\text { coefficient } \\
(\mathrm{m} / \mathrm{s})\end{array}$} & \multicolumn{3}{|c|}{$\begin{array}{l}\text { Parameters used in the } \\
\text { Fredlund-Xing Model }\end{array}$} \\
\hline & & & & & & & $a$ & $n$ & $m$ \\
\hline Subgrade & clayey sand & 2.67 & 0.38 & & .74 & $5 \times 10^{-7}$ & 7.74 & 1.93 & 0.29 \\
\hline Foundation & $\begin{array}{l}\text { medium } \\
\text { sand }\end{array}$ & 2.68 & 0.42 & & .73 & $2 \times 10^{-6}$ & 7.32 & 0.75 & 0.69 \\
\hline
\end{tabular}

\section{Simulation results}

Figure 2 presents the humidity distribution in the subgrade at flood water level at different rainfall durations, 1-day, 2-day and 4-days. As shown in Figure2a, after 1 day rainfall, the bottom of subgrade is in the saturated condition, which means all voids among soil particles is fill with water. The saturation line is higher on river side due to flood water level. The height of the saturation line gradually decreases through the subgrade to the dry side. The humidity decreases as the depth reduces.

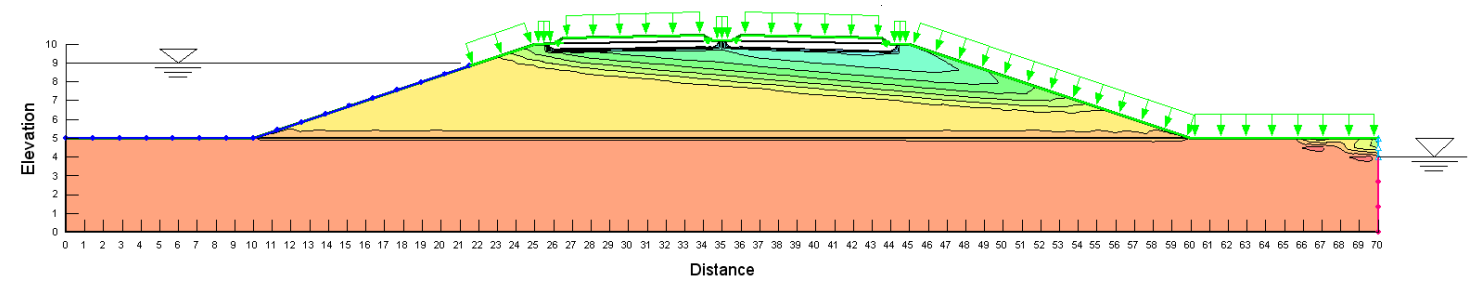

a) $1 \mathrm{~d}$

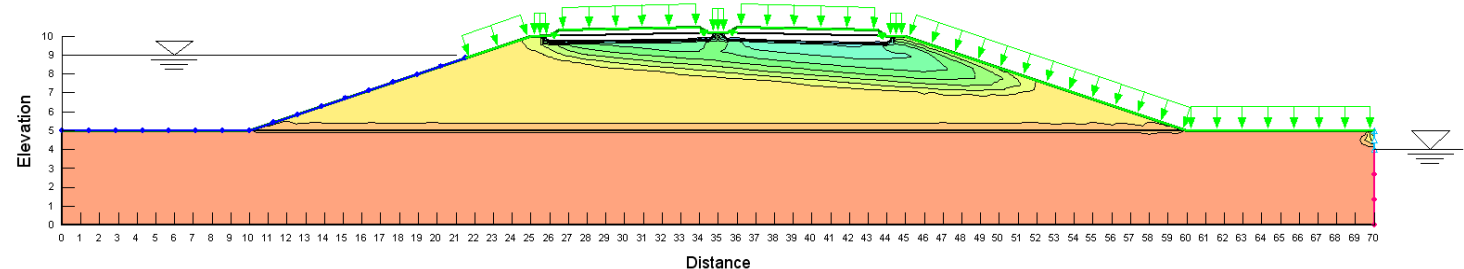

b) $2 d$

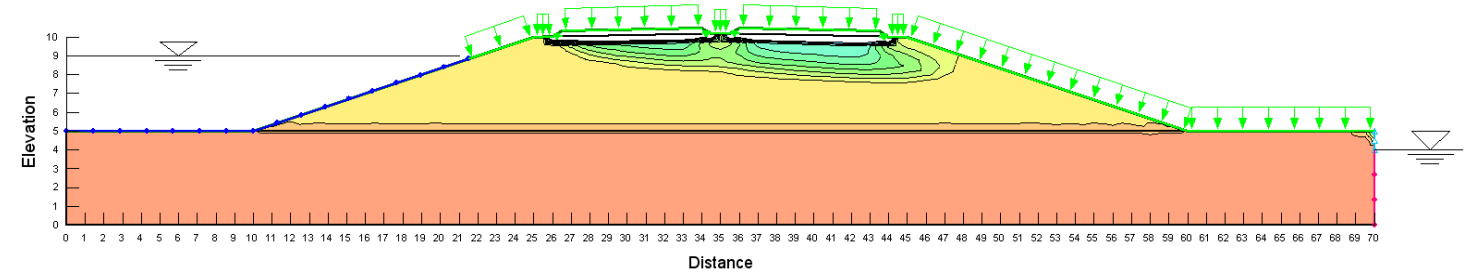

c) $4 \mathrm{~d}$

Figure 2 Contours of subgrade humidity field affected by rainfall duration on flood level

Figure $2 b$ shows the humidity distribution after two day rain fall. Generally, the humidity distribution pattern is similar to the one after one day rainfall. As the duration of rainfall increases, the overall among of water that gets into the subgrade increases. Therefore, the level of saturation line rises. After 4-day rainfall, the raise of the saturation table is more significant. On the dry side, the saturation line moves up from the corner of the subgrade to the upper 1/3 of slop. And on the river side, the 
saturation line already moves to the pavement shoulder. In such condition, the strength of the subgrade would dramatically decreases.

Fig 3 shows the moisture content distribution in the subgrade at the depth of $80 \mathrm{~cm}$ for the flood level water condition. The subgrade within the depth of $80 \mathrm{~cm}$ is called roadbed, which play an important role in supporting the moving traffic load and distributing the load to the lower subgrade. The roadbed needs to stay in a relatively dry condition. Fig2 shows that the moisture content decreases form the river side to the dry side. Asphalt pavement greatly reduces the amount of water that get into the subgrade.

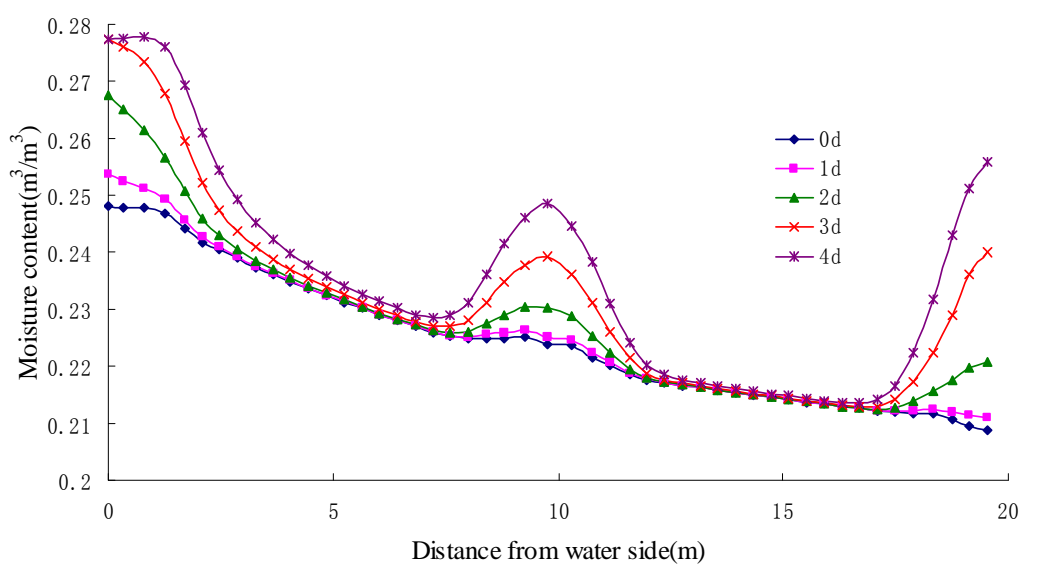

Figure 3 Moisture content distribution at the depth of $80 \mathrm{~cm}$ on flood water level

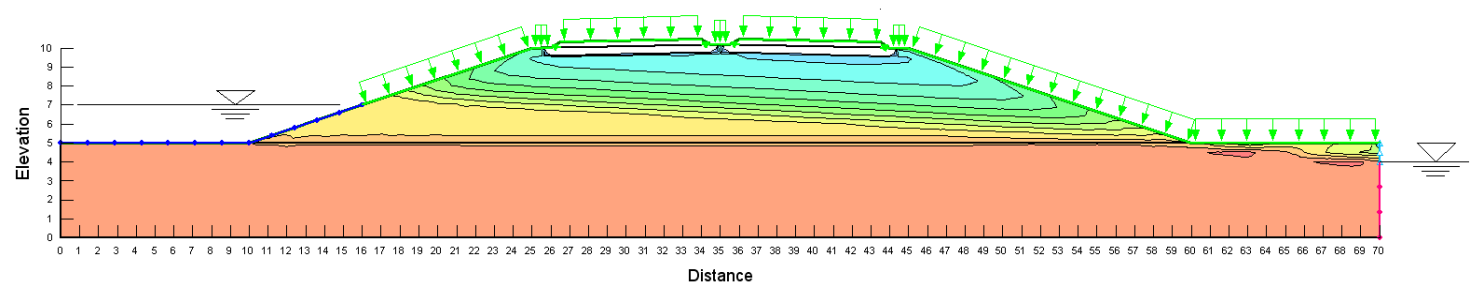

a) $1 \mathrm{~d}$

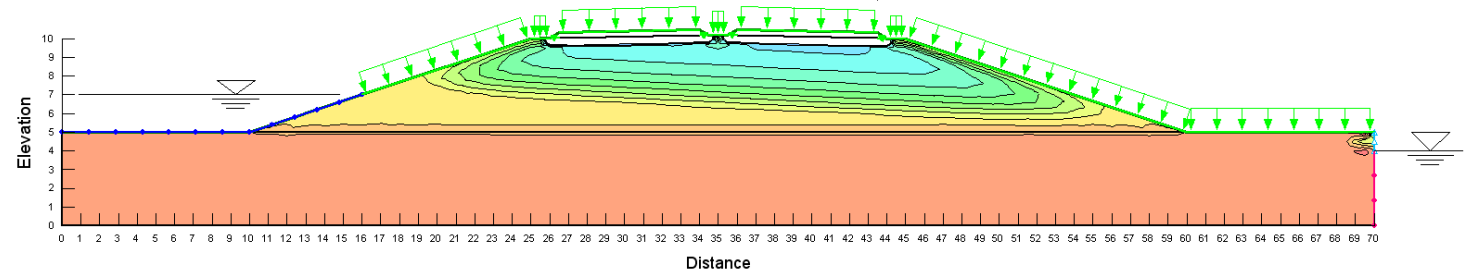

b) $2 d$

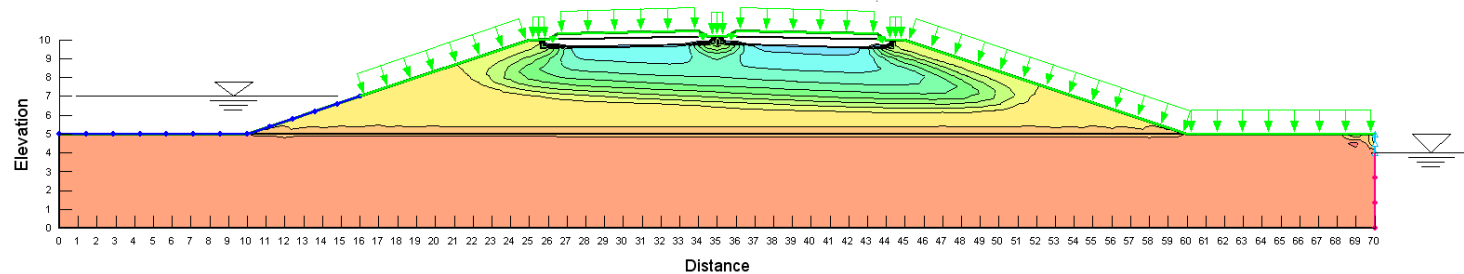

c) $4 \mathrm{~d}$

Figure 4 Contours of subgrade humidity field affected by rainfall duration on median water level

Figure4 show the humidity distribution in the subgrade at different rainfall durations when the river remains in the medium water lever. Generally, as the water lever on the river side decreases, the saturation table moves downs. As rainfall duration increases, the saturation table moves up. At the medium river water lever, the water-sealing effect of pavement becomes more pronounced. The 
humidity directly under the pavement surface is lower than that of the shoulder and pavement median, where the top of the pavement surface is not covered by a compacted asphalt mixture and the water can leak into the pavement and subgrade.

Figure 5 shows the moisture content distribution at the depth of $80 \mathrm{~cm}$ in the subgrade for medium water condition. General, the moisture content is lower than that of flood level water condition. The effect of the rainfall duration on the subgrade moisture content that directly under the asphalt pavement is minor.

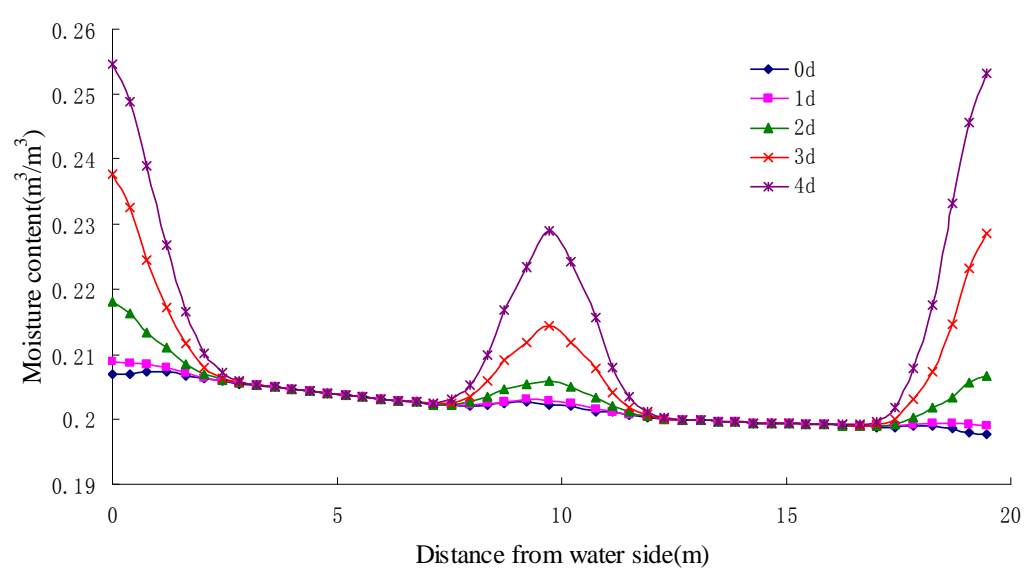

Figure 5 Moisture content distribution at the depth of $80 \mathrm{~cm}$ on medium water level

Figure6 shows the subgrade humidity distribution at low water level. It can be seen that the water level in the river bed overlaps on the ground line. The majority of the subgrade is in the unsaturated condition. After 1-day rainfall, the saturation table is under the ground line and only foundation is saturated. The humidity gradually decreases as the depth decreases.

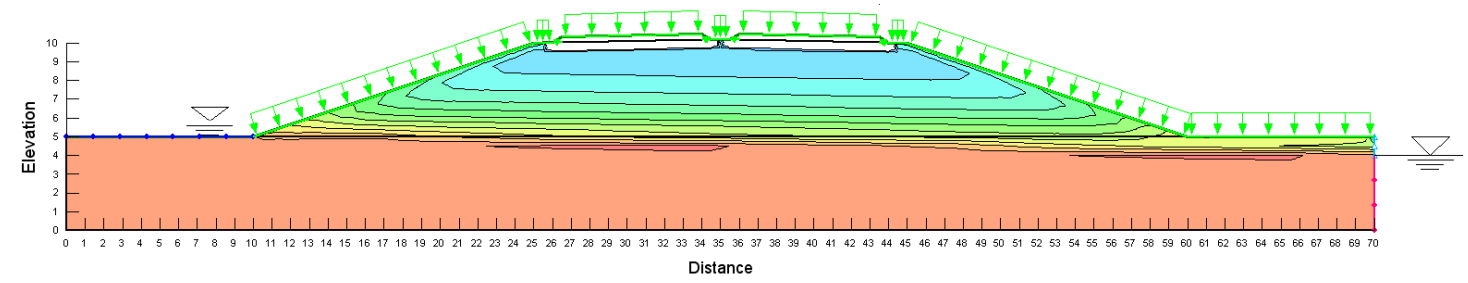

a) $1 \mathrm{~d}$

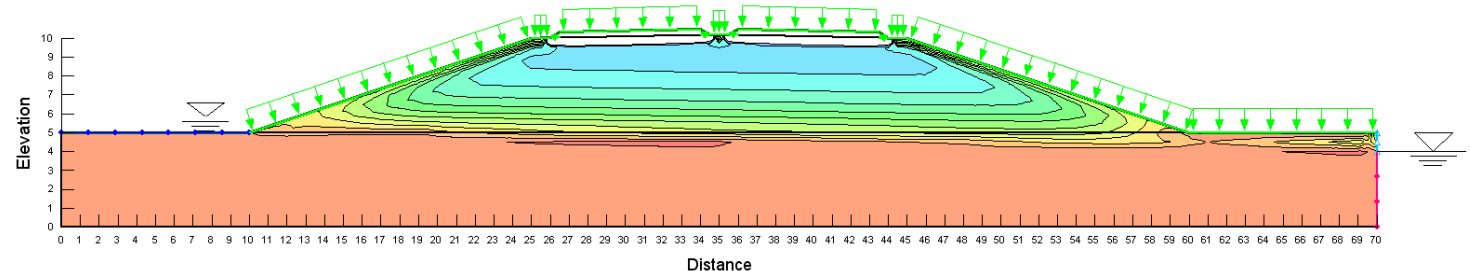

b) $2 d$

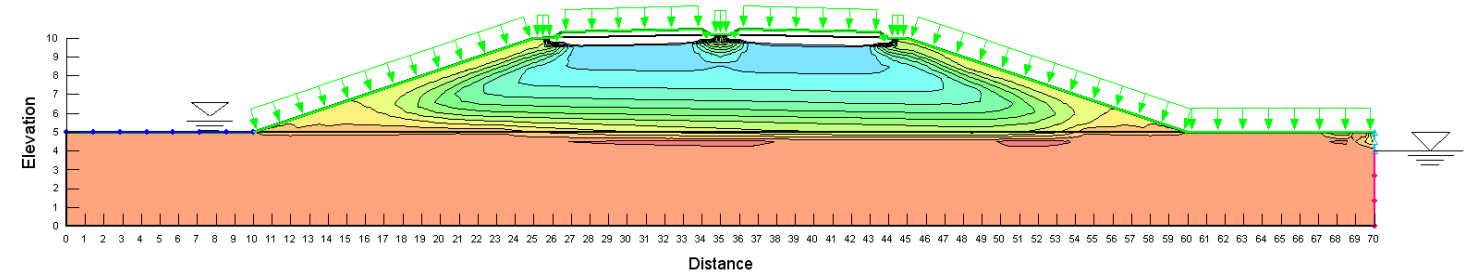

c) $4 \mathrm{~d}$

Figure 6 Contours of subgrade humidity field affected by rainfall duration on low water level

As rainfall duration increases, more water gets into the subgrade. The out layer of subgrade, i.e. area near the subgrade slop, the humidity increase significantly. On the other hand, due to the 
water-resistance property of asphalt pavement, subgrade directly under pavement surface remains in a relatively dry condition.

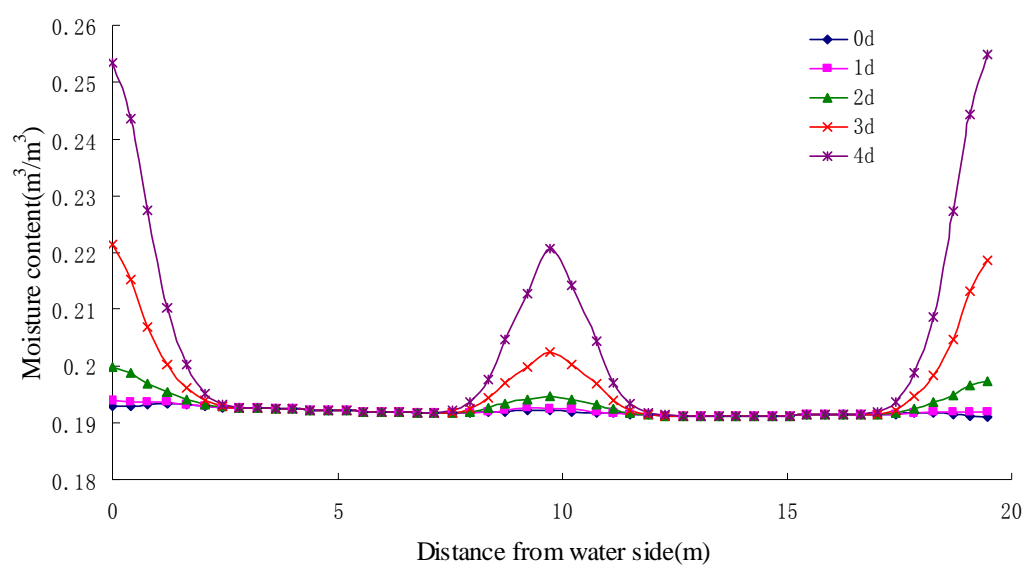

Figure 7 Moisture content distribution at the depth of $80 \mathrm{~cm}$ on low water level

\section{Conclusion}

In this study, a saturated-unsaturated seepage model has been adopted in the SEEP/W module to conduct numerical simulation on the humidity distribution of levee subgrade. It has been found that:

The river water lever affects the humidity distribution in the levee subgrade greatly. As water level increases, the saturation table increases.

As the rainfall duration increase, the saturation table increase.

Due to the water-resistance property of asphalt pavement, subgrade directly under covered area is less affected by rainfall and remains a relatively dry condition.

\section{Reference}

[1] HAO Wei. Reflections on function classification of levee road [J].South-to-North Water Diversion and Water Science \& Technology , 2013,11(5):168-171. (in Chinese)

[5] HUANG Xiao-Ming. Road Subgrade and Pavement Engineering[M]. Beijing: China

Communication Press, $2014: 4$.

[2] JTG D30-2015, Specifications for Design of Highway Subgrades [S]. Beijing: China

Communication Press, 2004. (in Chinese)

[3] JTG D50-2006, Specifications for Design of Highway Asphalt Pavement [S]. Beijing: China Communication Press, 2006. (in Chinese)

[4] JTG D40-2011, Specifications for Design of Highway Cement Concrete Pavement [S]. Beijing: China Communication Press, 2011. (in Chinese)

[6] LIU Zhijun. Numerical study of subgrade humidity field evolution with different compaction models [J]. Journal of Central South University (Science and Technology), 2014,45(4):1341-1346. (in Chinese)

[7] Tang Jianjun. Fine characterization of the state of roadbed equilibrium moisture associated with the complex environment Factors [D] .Chongqing:Chongqing Jiaotong University ,2014.

[8] LIU Jie, YAO Hai-lin, HU Meng-ling. Moisture Changes and Influencing Factors of Unsaturated Soil Subgrade under Atmospheric [J]. Journal of Shanghai Jiaotong University, 2011,45(5):772-776. (in Chinese)) 